História e Perspectivas, Uberlândia (57): 179-207, jul./dez. 2017

http://dx.doi.org/10.14393/hep-v30n57-2017-7

\title{
HISTÓRIA, CONSCIÊNCIA HISTÓRICA E UTOPIA EM J. RÜSEN E A. HELLER: REFLEXÕES PARA A DIDÁTICA DA HISTÓRIA
}

\author{
Luis Fernando Cerri* \\ Caroline Pacievitch**
}

RESUMO: O artigo discute as posições de Jörn Rüsen e de Agnes Heller sobre consciência histórica e suas implicações possíveis para a Didática da História. Consciência histórica é entendida como um conjunto de processos para atribuir sentidos e significados quanto ao tempo e que se expressam em diferentes cenários. A argumentação se desenvolve cotejando as obras em que Rüsen e Heller discutem especificamente suas noções sobre consciência histórica, confrontados pelos desafios para a orientação temporal na pós-modernidade. Conclui-se que tal reflexão é relevante para a formação de historiadores e professores de história que enfrentam as dificuldades em construir sentidos históricos na pluralidade sem recorrer a explicações redentoras, mas ainda defendendo valores como a razão, a verdade e a democracia.

PALAVRAS-CHAVE: Didática da história. Teoria da história. Ensino de história.

ABSTRACT: This article discusses Jörn Rüsen and Agnes Heller statements about historical consciousness and their possible consequences to the History Didactics. Historical consciousness is taken as a ensemble of processes to assign senses and meanings

* Professor do Departamento de História, Universidade Estadual de Ponta Grossa, Programa de Pós-Graduação em História. Doutor em Educação.

** Professora do Departamento de Ensino e Currículo, Universidade Federal do Rio Grande do Sul. Doutora em Educação. 
about time, which expresses themselves in different scenarios. The argumentation is developed collating the works of Rüsen and Heller in which they discuss specifically their notions about historical consciousness, faced to the challenges to the temporal orientation at post-modernity. It is concluded that such reflection is relevant to the historians and history teachers training, who front difficulties on building historical meanings in a pluralistic way, without recurring to redeemer explanations, still considering values as reason, truth and democracy.

KEYWORDS: History didactics. Theory of history. History teaching.

\section{Introdução}

Criticar o relativismo nilista e apostar em mundos melhores, sem desbancar para soluções redentoras ou narrativas homogeneizantes, pode ser uma forma de caracterizar os pensamentos de professores e professoras de história sobre sua profissão, pois evitam resumir suas perspectivas políticas a um único parâmetro político ou ideológico, mas também se recusam a afirmar que são neutros. Além disso, estão cientes de que manter posicionamentos políticos que amparam suas decisões profissionais e políticas não configura proselitismo político. Os dilemas que afetam a formação e a atuação profissional de professores de história não se resumem às suas opções político-partidárias, mas sim nas formas como atribuem sentido à profissão (formação, condições de trabalho, compreensão sobre conhecimento histórico, etc.) e seus objetivos mais amplos, conectados com o papel da escola e da história para o futuro dos jovens. Picuinhas políticas reducionistas não dão conta da complexidade que envolve o ensinar história na contemporaneidade.

A pergunta que muitos professores se fazem pode ser sintetizada em "qual é minha responsabilidade docente, perante 
minhas utopias político-educacionais e as demandas diversas expressas pelos jovens estudantes, por suas famílias, pela ciência histórica, pelo mundo do trabalho, pelos direitos humanos, pelas políticas públicas educacionais e por outras instâncias sociais?". Tal pergunta pode ser respondida de diversas formas, cada vez que se tomam decisões ao longo do exercício profissional. Professores trabalham com jovens que ainda estão formando suas compreensões sobre o tempo, mas já se movem entre opiniões, conceitos, juízos e projetos de futuro, sobre os quais o conhecimento histórico pode interferir.

Por isso, julgamos relevante refletir, do ponto de vista da Didática da História, sobre possibilidades de sistematizar estas variáveis e lançar novas luzes sobre esta pergunta. Uma forma de fazer isso é dialogar com pensadores dedicados ao tema, comparando-os e submetendo suas ideias ao crivo dos questionamentos específicos do ensinar e aprender história. Neste artigo, escolhemos dialogar com Jörn Rüsen e Agnes Heller por três razões principais: a) seus escritos foram dedicados, em alguma medida, aos processos educativos, não diretamente por eles, mas por seus intérpretes; b) são autores que se posicionam pela democracia e apostam, de forma mais ou menos intensa, no papel do intelectual como cidadão que deve contribuir para o coletivo; c) suas ideias permitem aproximações e afastamentos a partir de suas concepções de história, consciência histórica e utopia, o que interessa diretamente à didática da história.

$\mathrm{O}$ conceito de consciência histórica ganhou destaque nos trabalhos que se dedicam às articulações entre a teoria da história e a didática da história, na última década no Brasil. Esse movimento é documentado, por exemplo, por Barom (2012). O principal autor referenciado nesse debate no Brasil é Jörn Rüsen, embora ele esteja longe de ser o único a abordar e discutir o conceito de consciência histórica (CERRI, 2001) e de ser acatado indisputadamente (p. ex., LAVILLE, 2005). Rüsen, como veremos adiante, filia-se a uma vertente de pensamento que o conduz a uma determinada concepção de consciência histórica que é distinta, por exemplo, daquela que Gadamer 
(1998) sustenta, de consciência histórica como resultado de uma tomada de consciência da historicidade do mundo típica da modernidade ocidental. Rüsen pode ser contado entre os tributários do pensamento de J. Habermas, por sua vez é um dos debatedores de Gadamer. Em linhas gerais, para Jörn Rüsen, a consciência histórica é um atributo humano, um componente da sua consciência, que varia em termos de forma e de conteúdo de acordo com a cultura em que se insere, mas tem sempre a mesma função: atribuir sentido ao tempo, mapeando a realidade e estabelecendo referenciais identitários a partir dos quais se navega na dita realidade.

A característica humanista da perspectiva rüseniana sobre a consciência histórica, em sentido amplo, ou seja, como reconhecimento da horizontalidade nas diferenças entre as culturas, permite um cotejamento com a perspectiva de Agnes Heller sobre o mesmo conceito de consciência histórica e suas consequências utópicas. Pensamos que esta análise comparada permite tanto ampliar e aprofundar a compreensão sobre o conceito, extrapolando o que seria a compreensão dele em cada leitura feita isoladamente, quanto refletir sobre possíveis implicações - nem sempre diretas - para o pensamento sobre o ensino de história.

Pretendemos argumentar que Rüsen e Heller não só participam de um paradigma científico comum como também convergem no que se refere à atitude diante do processo de transformação dos paradigmas. O próprio conceito de paradigma científico, de T. Kuhn (1998), permite compreender as proximidades e as coincidências do pensamento de dois autores de formações, lugares e espaços epistemológicos distintos, e permite explicar as aproximações entre suas teses como tentativas separadas de dar respostas aos mesmos questionamentos postos pela realidade contemporânea. Em ambos, estão presentes intersecções entre filosofia e cultura.

Nesse texto, propomos um trajeto que parte de uma breve contextualização do pensamento de Rüsen e de Heller, segue para aproximações em torno do conceito de consciência histórica e uma 
conclusão a partir dos desafios da consciência histórica diante da pós-modernidade. Trata-se do modo genético de produção de sentido, em Rüsen, e da responsabilidade planetária, em Heller. Em ambos os conceitos, se vislumbra uma projeção esperançosa diante do futuro, tema que consideramos essencial para o ensino de história e a constituição profissional de seus professores.

Contextos: dois humanistas em diálogo com a pósmodernidade

A obra de Heller transformou-se com o passar dos anos e dá lugar a interpretações diversas (SEVILLA, 1998; TORMEY, 1998; GRANJO, 2008). No Brasil, sua obra é conhecida, principalmente, pela mobilização do conceito de cotidiano para a compreensão de temas educacionais (GUIMARÃES, 2002; DUARTE, 2006).

Agnes Heller nasceu na Hungria e instruiu-se na tradição marxista. Foi discípula de G. Luckács e mudou-se, em 1978, para a Austrália e, depois, para os Estados Unidos, concomitantemente ao seu progressivo afastamento, primeiro de Marx e depois do próprio Luckács. Esse deslocamento, por outro lado, também se liga às suas indagações radicais sobre a liberdade e a autonomia diante da produção e reprodução das necessidades. Como sua obra é diversa e multifacetada, adotou-se como base para este artigo o livro "Uma teoria da história", publicado originalmente em 1981 e traduzido para português brasileiro em 1993.

Nessa obra, a filósofa discute possibilidades de uma política emancipadora e socialista, a partir da crítica a filosofias redentoras. O objetivo do livro é a construção teórica de um projeto de ação para transformação do mundo que não seja totalitário. O primeiro passo - e uma das instâncias onde se expressa seu acolhimento às críticas pós-modernas - é negar as filosofias da história que se propõem redentoras e determinam o futuro como necessidade. Heller propõe a substituição das filosofias da história por uma teoria da história engajada nos ideais de liberdade, igualdade e fraternidade.

Ela propõe o engajamento individual para o bem coletivo, 
a fim de trabalhar por uma sociedade melhor, na qual nenhuma vida humana sirva como meio para a satisfação de necessidades de outros indivíduos, tampouco de projetos coletivos (HELLER, 1993). Heller denomina "responsabilidade planetária" o estágio da consciência histórica em que é possível esse tipo de engajamento, baseado na ideia de progresso e a valores humanistas. ${ }^{1}$

Agnes Heller pode ser compreendida como uma pensadora radical, em busca de compreender o tempo presente e de refletir sobre significados da existência humana. Ela debate os limites da historiografia europeia ocidental; reafirma a possibilidade (e não a necessidade) do socialismo; e valoriza liberdade, igualdade e fraternidade vividas em espírito democrático e plural. $\mathrm{O}$ compromisso individual com um projeto de futuro se reveste de sentidos coletivos, mas também individuais, ligados à angústia de viver num mundo injusto.

Embora seja frequente conectar utopia e educação (BACZKO, 1989), a escola não é tema considerado detidamente em sua obra, muito menos o ensino de história. Entretanto, a noção de que é preciso aprender com a história se mostra nas últimas páginas de "Uma teoria da história": "[...] O aprendizado com a história, com o passado de nosso presente [...] significa aprender a selecionar determinados objetivos e decidir quais, dentre esses, podem ser compartilhados" (HELLER, 1993, p. 394-395).

Jörn Rüsen nasceu e desenvolveu sua carreira acadêmica

1 Compreende-se Humanismo conforme Marilena Chauí: "o humanismo, [...] distanciando-se do teocentrismo medieval, [...] dá ao homem o lugar central. Desenvolve a ideia de que o homem é dotado de capacidade e força não só para conhecer a realidade, mas sobretudo para transformá-la, ideia que transparece num adágio que será celebrizado por Francis Bacon: 'o homem é o arquiteto da Fortuna', ou seja, o homem é senhor de sua sorte ou de seu destino. [...] Essa ideia da racionalidade e do poder da vontade conduz a duas outras ideias, essenciais para o surgimento das utopias: a de que os homens valem por si mesmos, independentemente de privilégios de nascimento e sangue, de maneira que a oposição entre ricos e pobres é injusta e fonte das revoltas que destroem os Estados; e a de que é possível organizar um Estado sereno, feliz, glorioso e perfeito, fundado na equidade e dirigido por um verdadeiro príncipe." (CHAUÍ, 2008, p. 8-9). 
na Alemanha, e testemunhou sua divisão e unificação. Liga-se às tradições do iluminismo e do historicismo alemão, sendo estudioso do historiador oitocentista J. Gustav Droysen (ASSIS, 2010, p. 8). Sua obra coloca-o como um nome de destaque dentro da tradição alemã de reflexão sobre as ciências humanas. Atualmente, dedicase aos estudos sobre o humanismo no contexto da globalização.

A obra de Rüsen de maior conhecimento e difusão no Brasil é a trilogia em que sintetiza suas considerações sobre a teoria da história: "Razão História" (RÜSEN, 2001), "Reconstrução do passado" (RÜSEN, 2007a) e "História viva" (RÜSEN, 2007b). Os livros vieram a público originalmente na Alemanha dos anos 1980. O sentido geral das obras é de dar conta, numa compilação e síntese compreensiva da teoria da história, dos avanços teóricos e metodológicos vividos pela disciplina até o final do século $X X$.

No que tange à didática da história, Rüsen participa de um grupo de historiadores alemães que se preocuparam com as articulações entre reflexão didática e teoria da história, galvanizadas pelo conceito de consciência histórica. Schörken, Bergmann, Pandel e Jeismann, segundo Saddi (2014), formam, com Rüsen, os principais nomes dessa trajetória intelectual, que procurou responder à crise de continuidade da cultura história alemã, marcada pelo conflito geracional do final dos anos 1960 .

A consciência histórica, nesse grupo de reflexão, é definida em sentido amplo como o conjunto dos procedimentos mentais pelos quais, individual e coletivamente, o passado é assimilado e avaliado como experiência pessoal e experiência transmitida, o presente é decifrado como campo das decisões e ações em vista das expectativas definidas para o futuro. Em suma, tratase do modo pelo qual os grupos dão sentido ao tempo e agem de acordo com este sentido. O que explica a proficuidade desse conceito no enfrentamento das divergências intergeracionais, assim como as questões da cultura histórica alemã em função do enfrentamento do passado nacional referente ao holocausto judeu. Rüsen qualifica essa virada na didática da História como um elemento integrante da mudança de paradigma pela qual o estudo da disciplina passou na então Alemanha Ocidental, 
articulada pelos historiadores preocupados com a educação (RÜSEN, 2006, p. 11).

Cardoso (2008) indica ainda que o conceito de consciência histórica é uma referência fundamental para o trabalho de reflexão que Rüsen desenvolve sobre a própria história, a historiografia e a teoria da história. Isso se dá uma vez que a consciência histórica é definida pelo autor alemão como o modo essencial da relação humana com o tempo. Essa relação se desenvolve de várias outras formas, sendo que a ciência da história nada mais é que uma forma metodizada e altamente racionalizada daquela relação essencial do homem com o tempo (CARDOSO, 2008, p. 161).

Rüsen enfrentará os dilemas postos pela pós-modernidade para o campo da história e sua relevância social com uma postura permeável à crítica, mas firmemente estabelecida em torno da razão como princípio. Essa postura fica bem expressa na epígrafe de um dos seus dois textos publicados no Brasil no calor das discussões sobre a pós-modernidade, ensejados pelos amplos efeitos da globalização e no exato contexto da queda do muro de Berlim: "O sonho da razão produz monstros". Presente em uma das obras do pintor Goya, essa frase é epígrafe do texto "Conscientização histórica frente à pós-modernidade" (RÜSEN, 1989). Outro artigo do autor num contexto parecido é "A história entre a modernidade e a pós-modernidade" (RÜSEN, 1997). O debate do autor com o linguistic turn, principalmente com Hayden White, é sumarizado no volume "História viva" (RÜSEN, 2007b), da trilogia publicada pela editora da UnB. A reafirmação da possibilidade de razão por meio da ciência histórica, rediscutida e condicionada pela crítica pós-moderna, aparece novamente no conjunto de ensaios de Rüsen publicado recentemente no Brasil (RÜSEN, 2014).

Quanto à crítica pós-moderna mais geral sobre a possibilidade de razão na história, alinhavamos a seguir alguns pontos essenciais da argumentação do autor na intenção de sumarizá-la, sem pretensões de completude ou grande precisão. Essencialmente, Rüsen rejeita as afirmações de uma pós-história, ao não aceitar a própria ideia de fim da história; refuta a impossibilidade de a 
história produzir orientação histórica com base na racionalidade; reafirma a necessidade de uma representação mental da unidade da experiência histórica, embora aceite a negação de uma história única, universal, em favor da convivência de histórias diversas. Por fim, aceita a superação da ideia de que as formas de vida do passado evoluíram no sentido das formas de vida do presente, concordando com a perspectiva de múltiplas possibilidades de futuro que compõem as várias partes do passado e que não se realizaram no presente.

Quanto à crítica específica do linguistic turn sobre a impossibilidade de a história produzir discursos sobre o passado que se diferenciem da literatura de ficção, a argumentação de Rüsen, em resumo, devolve a crítica à própria concepção inadequada de história que, para ele, sustenta o questionamento de cariz pós-moderno. Aproximar historiografia de discurso literário ficcional porque as fontes através das quais o historiador reconstrói o passado não são o passado em si, mas representações dele, implica assumir que há uma instância, ainda que inacessível ou dificilmente acessível, de facticidade pura. Pelo contrário, a reflexão histórica predominante na atualidade reconhece que há uma dimensão interpretativa desde a própria seleção das fontes e presente na reconstrução do passado que se sustenta nelas. Ao assumir essa perspectiva, Rüsen reconhece que o componente poético e retórico da narrativa histórica científica, embora tenha sido desprestigiado na trajetória da disciplina ao longo do século $X X$, não é incompatível com a reivindicação de cientificidade da História. Pelo contrário, responder aos desafios atuais à história passa, para o autor, pela reintegração teórica e prática destas dimensões.

Em síntese, tanto Rüsen quanto Heller coincidem no acolhimento a aspectos relevantes da crítica pós-moderna sobre o conhecimento racional e sobre o projeto político-social da modernidade. Esse acolhimento, que faz aceitar e incorporar críticas aos postulados da modernidade nascidos, entre outras tradições, no humanismo, não significa um abandono das pretensões de racionalidade do conhecimento, tampouco das 
promessas de liberdade, igualdade e fraternidade. Significa a atualização, o redimensionamento e o aprofundamento desse projeto científico e sociopolítico diante das profundas contradições e dos radicais desafios introduzidos pela história do século XX.

\section{Consciência histórica, um conceito comum}

A consciência histórica é um dos conceitos que pertencem à ordem de abstrações que procuram construir significado para o próprio exercício humano de abstrair e construir significado. Pertence ao grupo de conceitos que procura entender os fenômenos do pensamento humano coletivo, do qual participam também conceitos como imaginário, ideologia, mentalidade. Em todos os casos, a definição e a delimitação do campo da realidade ao qual os conceitos se referem são objeto de discussões e da formação de diferentes linhas teóricas. Com o conceito de consciência histórica não é diferente: há pelo menos dois grandes grupos de interpretação, um que estabelece a consciência histórica como recurso escasso ao qual se pode aceder mediante determinadas condições e esforços, e outro que considera que a consciência histórica é uma constante antropológica, uma condição da existência humana. ${ }^{2}$

Jörn Rüsen e Agnes Heller, em condições e contextos diferentes, pertencem ao grupo dos que definem a consciência histórica como elemento inerente ao pensamento humano. Cotejar as diferenças e semelhanças nas definições de ambos serve para verificar até onde vai a compatibilidade entre suas definições e descrições do conceito, bem como colaborar para compreendê-lo melhor. Avaliamos que assim será possível identificar quais as contribuições dos autores a uma reflexão teórica da História que se importa com a dimensão didática, entendida amplamente como a disciplina de compreensão de uma economia (produção, distribuição e consumo) ou uma antropologia/epistemologia (CHEVALLARD, 2009) do conhecimento histórico socialmente compartilhado.

2 Sobre o histórico do conceito e suas variações, ver: Cerri, 2001; Laville, 2005; Cardoso, 2008. 
A obra "Uma teoria da história", em que se trabalha o conceito de consciência histórica em busca da formulação de uma teoria da história, é ponto de inflexão na obra de Heller. Apesar de considerar que, para o século XIX, Marx elaborou uma filosofia da História adequada, ela entende que a atualidade exige uma postura crítica, propondo uma teoria da história que não imponha o "dever ser", mas o tome como escolha racional, possibilidade e projeto. São igualmente rejeitadas perspectivas irracionais e desesperançadas sobre o presente e filosofias da história que postulariam a produção como variável independente da história.

Assim, ela reflete num sentido próximo ao de Hannah Arendt, que também delineou sua crítica a Marx a partir do impedimento ao Novo que poderia se desdobrar de seu pensamento. Heller identifica que as ideias de progresso e de leis gerais da história são uma criação da civilização moderna no final do século XVIII, não uma lógica universal que se aplique a qualquer tempo (GRANJO, 2008 , p. 18-20). Isso não significa que a noção de progresso seja descartada de sua teoria da história. ${ }^{3}$ A longa reflexão sobre os estágios da consciência histórica, na primeira parte de "Uma teoria da história", não tem um fim em si mesma, pois é a base para seu próprio projeto de presente e de futuro. Na obra de Rüsen, o conceito de consciência histórica tem um caráter transversal, ocupando um espaço privilegiado entre outros conceitos-chave, embora vá sofrendo pequenas orientações e ajustes ao longo do processo de diálogo com outros autores e com diferentes contextos sociopolíticos e culturais.

Para Agnes Heller, consciência histórica é a "[...] resposta à pergunta - 'De onde viemos, o que somos e para onde vamos'" (HELLER, 1993, p. 15). Para Jörn Rüsen, a consciência histórica pode ser definida como "[...] a suma das operações mentais com as quais os homens interpretam sua experiência da evolução

Heller define progresso como todo tipo de ação cujos resultados são sempre ganhos, sem perdas correspondentes, isto é, sem sofrimento humano. Entretanto, ele é tido como ideia reguladora e não como realidade factual (HELLER, 1993, p. 355 et seq.). 
temporal de seu mundo e de si mesmos, de forma tal que possam orientar, intencionalmente, sua vida prática no tempo" (RÜSEN, 2001, p. 57). Heller, interessada em construir propostas de ação para a humanidade e Rüsen, preocupado com os rumos da historiografia, tratam da mesma coisa: o fenômeno cultural pelo qual pessoas e grupos dão sentido ao tempo e a si mesmos no tempo. O conteúdo dessas respostas é construído por Heller e Rüsen com estratégias e com substâncias distintas. Rüsen busca, na caracterização da consciência histórica, uma estrutura de tipos ideais progressivamente mais complexos, enquanto a estratégia de Heller tem a ver com a conceitualização a partir de referências a cenários históricos que, embora presos a uma sequência canônica associada à grande narrativa da história ocidental, pretende ser significativa para além dos casos particulares:

Esta é a razão pela qual, ao recapitularem-se os estágios da consciência histórica, nenhuma tentativa foi feita para recapitular qualquer período histórico, qualquer história. Sequer tentei reconstruir períodos reais e a história real de cada um, ressaltei apenas seu auto-entendimento como historicidade. Dentro da estrutura dessa reconstrução, nenhum estágio de desenvolvimento da consciência histórica poderia ser compreendido como o resultado daquele que o antecedeu, posto que cada estágio de consciência fui abstraído do desenvolvimento (ou "desdobramento") efetivo e das mudanças reais; de suas lógicas e motivações próprias. (HELLER, 1993, p. 391).

Para ambos os autores, trata-se de afirmar e procurar montar um quadro prévio de possibilidades para a diferenciação e a dinâmica do fenômeno, sendo que o foco é a necessidade de oferecer possibilidades de orientação em tempos de grandes incertezas e ameaças antidemocráticas.

Em Rüsen, a consciência histórica aparece primeiramente desagregada em quatro tipos: tradicional, exemplar, crítico e genético. Mesmo advertindo que se tratam de ideais e não de uma taxonomia de consciências encontráveis empiricamente, foi 
comum que se pensasse em cada um dos tipos como essências da consciência histórica de indivíduos concretos, estabelecendo como objetivos educacionais a relativização dos tipos básicos para a instauração dos tipos mais complexos ou sofisticados (ver, p. ex., PARANÁ, 2008, p. 58-60). Posteriormente, Rüsen adotará a nomenclatura modos de geração de sentido histórico, referindo-se às narrativas (RÜSEN, 2007b) produzidas pelos sujeitos. Entendemos esse deslocamento como um refinamento da análise: da afirmação de essências do ser (inacessíveis à investigação empírica) à afirmação de produtos (narrativas) da ação dos sujeitos concretos, que tendem a ser mais complexos do que a tipologia.

Os modos de geração de sentido histórico rüsenianos denotam, a nosso ver, uma gramática pela qual as consciências históricas se expressam. Em vez de essências (ainda que móveis) dos seres, trata-se mais de prever/descrever logicamente os modos de geração de sentido como uma espécie de vocabulário, uma caixa de ferramentas linguística que fornece ao usuário capaz de manejá-las a habilidade de dizer - portanto, entender - a historicidade própria de seu mundo. Cada modo nasceu em uma situação histórica diferente, daí a sua progressão em termos de complexidade. O fato, entretanto, de que os contextos que ensejaram o surgimento e funcionamento de cada modo de geração de sentido não permite assumir que desapareceram quando desaparece o respectivo conceito. Pelo contrário: como as palavras, os modos de geração de sentido permanecem disponíveis para as sociedades, para a produção de todo tipo de narrativas, mesmo que seu uso seja limitado ou pouco frequente.

Num brevíssimo sumário, os modos de geração de sentido histórico em Rüsen são quatro: tradicional (a narrativa anula o tempo, com o que aumenta a força do passado no condicionamento do presente, às vezes indiferenciando qualitativamente o passado e o presente, ou "encapsulando-o" de modo que ele não seja notado como passado); exemplar (a narrativa acolhe a diversidade de passado e presente, torna o tempo abstrato ao eleger situações universais em que, em geral, se repetem princípios, nos quais o 
passado é tomado como exemplo para significar o presente e o futuro); crítico (a narrativa nega os fundamentos e as condições de validade das narrativas anteriores); e genético (a narrativa "temporaliza" o tempo, ou seja, absorve a historicidade, a relatividade e a mudança como condições do significado atribuído ao tempo).

Os quatro modos variam, desde nossa perspectiva, a partir de três pares de fatores: coletividade/indivíduo; passividade/atividade do sujeito; passado/devir. Com isso, afirmamos que, nos primeiros modos, a produção de sentido repousa na coletividade, e tende a ser única ou monolítica, enquanto, nos últimos, a produção de sentido pende para os indivíduos ou pequenos grupos, e por isso fragmenta-se. Vai-se da maior passividade à maior atividade dos sujeitos isolados, quando se transita do modo tradicional rumo ao modo genético. Por fim, o centro de gravidade do sentido produzido desloca-se sucessivamente do passado para o futuro, conforme se transita do modo tradicional ao genético. Ao conviver no presente, os quatro modos dão conta da diversidade de situações nas quais os indivíduos e grupos significam-se e significam o mundo no tempo, mas é lícito pressupor que as pessoas e os grupos dominam (ou deixam de dominar) e usam (ou deixam de usar) de forma desigual os quatro modos de geração de sentido histórico.

Agnes Heller, por sua vez, trata de "estágios da consciência histórica". Para descrevê-los, utiliza uma sequência canônica de contextos históricos que vai dos tempos primitivos à pósmodernidade, associando a cada um deles um estágio da consciência histórica. Vamos contra as aparências quando sustentamos a interpretação de que não se trata de um esquema evolucionista ou etapista, que de resto não seria consistente com a fase do pensamento de Heller em que esta obra vem a público. Ela reconhece que não escreveu sobre todas as representações possíveis sobre o tempo, mas que se concentrou naquelas que diziam respeito, em suas palavras, à "nossa história" (HELLER, 1993, p. 391), justamente para criticar seus limites e construir outras possibilidades. Como visto, essas possibilidades não abrem 
mão do compromisso individual por um ideal, que deve, entretanto, se submeter aos valores de liberdade, igualdade, fraternidade, democracia e pluralidade (HELLER, 1993, p. 367 et seq.).

A sequência de estágios não tem um valor ascendente, mas termina em confusão e em possibilidade e não vai além do presente daquele momento. Por isso, entendemos "estágios" não como degraus, mas como contextos, cenários ou até mesmo "palcos", que seria uma tradução possível do termo em inglês, stages, utilizado pela autora em seus originais. Nossa leitura é a de que Heller recorre ao esquema de contextos históricos típico da narrativa canônica da história ocidental em busca de conjunturas históricas que permitam associar as variações na consciência histórica às sucessivas respostas às perguntas "quem somos, de onde viemos e para onde vamos", que, ao mesmo tempo, constituem a consciência histórica de um tempo e fazem/ produzem sentido dentro dele. Por isso, a tipologia de Heller não tem a necessidade de ser exaustiva, já que sua função não é explicar toda a história, mas teorizar a relação entre a historicidade e as construções humanas e sociais do sentido do tempo.

A categorização de Heller para a consciência histórica é baseada na noção de generalidade, que significa a condição pela qual a origem do sistema de valores, modo de vida e instituições de um grupo é associada - pelo grupo - à própria origem do universo; é o oposto de universalidade, que é a condição pela qual o grupo entende que todos os seres humanos partilham da mesma origem, independentemente de seus valores, hábitos e instituições. A generalidade pode ser não refletida e refletida: no primeiro caso, a condição humana é entendida como restrita ao clã ou tribo, e, no caso da generalidade refletida, a condição humana é entendida como não-privativa da própria tribo ou clã.

Mais que explorar a terminologia criada por Heller para tipificar os diferentes estágios da consciência histórica, cumpre identificar as características de cada estágio com o contexto histórico ao qual é associado, com o fim de compreender como a autora descreve as características da consciência histórica em cada um deles. Cumpre afirmar ainda que o quadro geral dos 
estágios da consciência histórica de Heller é estruturado pela ideia de identidade coletiva.

A ideia de generalidade não refletida pode ser pensada como estrutura básica para o modo tradicional de geração de sentido de Rüsen. Como tal, sobrevive na contemporaneidade sempre que algum fator da cultura histórica desaparece do horizonte de elementos históricos, isto é, passa despercebido, é tomado como fora da história, isento de historicidade, sem tempo. O tradicional está ligado a alguma forma de narrativa de origem que estrutura ordens e comportamentos, mesmo dentro das sociedades modernas e pós-modernas. Grosso modo, um exemplo poderia ser o "descobrimento do Brasil pelos portugueses", mito de origem que permite ordenar-nos pela condição europeia. A autora admite um estágio próximo a esse em que são reconhecidos outros grupos humanos; mas permanece a ideia de que a origem do universo está vinculada exclusivamente à origem do próprio grupo. Trata-se do estágio da generalidade refletida da consciência histórica. Neste estágio e no anterior, o tempo é praticamente imóvel, passado, presente e futuro são indistintos.

As raízes do modo exemplar de produção de sentido de Rüsen, a nosso ver, podem ser buscadas nas experiências gerais compiladas por Heller em torno dos conceitos de estágio da generalidade refletida em particularidade e universalidade não refletida. Nesses dois estágios, o tempo se move, quer dizer, o ontem deixa de ser igual ao hoje e ao amanhã. $A$ partir do registro escrito e do estabelecimento do Estado e da sucessão de governantes e outros personagens que são recordados, estabelece-se o movimento que torna possível o tempo. O comportamento do indivíduo passa a ser bom se é bom para o grupo, e, para isso, depende do conhecimento dos registros históricos e das leis, para que os bons sejam imitados e os maus (os que prejudicam o grupo) repelidos. O acesso aos registros tem esse poder de produzir a imitação dos bons porque o texto fundante não é passível de interpretação, não é relativizável, ele encarna princípios universais. Apesar disso, ou exatamente por isso, a ação individual ou coletiva é discutível, 
é possível argumentar quanto ao valor ou à legitimidade das ações, presentes ou passadas, a partir do referencial histórico estabelecido. Este é, a nosso ver, o mecanismo básico do modo exemplar de geração de sentido de Rüsen, ou seja, a seleção entre o positivo e o negativo a partir de referências anteriores que não estão em questão ou em discussão.

Ao invés de soterrados pelo tempo passado, esses estágios da consciência histórica sobrevivem na atualidade por meio de fenômenos antropológicos como o etnocentrismo (no sentido mínimo de condição para a formação de grupos estáveis, reconhecendo que o grupo ao qual pertencemos tem um algo mais que justifica nosso pertencimento a ele). Toda a pedagogia cívica das festas nacionais, nomes de ruas e panteões dos heróis da pátria sustenta-se como permanência de modos exemplares de geração de sentido. Podemos, por fim, lançar a hipótese de que os fundamentalismos religiosos e os conservadorismos comportamentais (a homofobia, por exemplo) são expressões extremas de modos exemplares de geração de sentido, reagindo a um contexto de mudanças constantes em que os referenciais estão em movimento e transformação.

As estruturas básicas de pensamento e narrativa crítica sobre a identidade no tempo estão presentes de formas distintas nos estágios da particularidade refletida em generalidade (cujos modelos são a renascença e o iluminismo) e da universalidade refletida (contextos da revolução francesa e da revolução russa). Para ambos os estágios, a narrativa histórica promove a negação das estruturas da produção de sentido dominante, propondo progressivamente outras bases de afirmação que buscam superar a versão anterior. No estágio da particularidade refletida em generalidade, estabelece-se que o grupo ao qual pertencemos constitui a cultura particular mais adequada à condição humana: o renascentista escolhe o passado clássico, o iluminista cerca-se da razão e do conhecimento científico para elevar-se em meio à superstição e ao tradicionalismo que combatem. No estágio da universalidade refletida, a história é reconhecida como o palco da ação de todos os grupos, que competem entre si a partir de 
diferentes projetos de futuro. Em ambos os casos, deixa-se de conceber a história como fado em função da ideia de história como palco da ação de indivíduos e grandes coletividades que podem alterar e dirigir seu rumo. Trata-se, afinal de contas, das consciências históricas do homem moderno, finalmente separado da natureza e buscando governá-la com gênio inventivo e trabalho, movendo recursos e populações para moldar o progresso.

Diferentemente dos modos de geração de sentido histórico de Rüsen, que por definição produzem sentido e orientação, Heller concebe, na sua categorização de estágios da consciência histórica, estágios que não produzem sentido e orientação, mas sim confusão. Trata-se do contexto da modernidade tardia, em que as promessas de racionalidade e liberdade criam sociedades e economias que produzem o contrário desses princípios prévios. Nesse quadro, constata-se que a racionalidade gera a irracionalidade: guerras em nível industrial, extermínio, racismo, destruição da cultura, possibilidade concreta da autoaniquilação da humanidade. Diante da falência dos valores, as ideias de verdadeiro e correto perdem sentido, e estabelece-se a possibilidade de descrença com todos os ideais.

Após a arrogância da ideia de controle sobre a história, abatese o sentimento de impotência do homem diante da história e o colapso simultâneo das filosofias da história. Por mais que se aprofunde a racionalização no pensamento, ela é concomitante com a irracionalidade das práticas. E o problema não está apenas nos negadores da ciência, que fundamentam seus raciocínios em conceitos fundamentalistas pré-modernos, mas nos próprios valores da modernidade, que geraram interesses econômicos e impulsos de consumo que não conseguimos, como coletividade, superar.

Heller nomeia três formas de filosofia da história que são típicas da confusão da consciência histórica: o "Instituto de Pesquisa da Factidade", o "Grande Hotel do Abismo" e o "Hospital Psiquiátrico/ Radicalização do Mal". O Instituto de Pesquisa da Facticidade representa o neopositivismo e a rejeição das questões de fundo em nome do pragmatismo. O Grande Hotel do Abismo representa o conformismo com o horror e a impossibilidade de redenção 
humana. Por fim, o Hospital Psiquiátrico e a Radicalização do Mal representam a perspectiva de absorver como identidade os processos que sofremos: entregar-se à violência, marginalização, patologização, fundamentalismos místico-religiosos.

Heller propõe que o estágio atual de consciência histórica seja pensado/construído como Responsabilidade Planetária, o que só é possível abandonando a ideia de que o futuro foi préestabelecido e, portanto, limita nossas ações (filosofia da história), e adotando o futuro como projeto com espaço para a pluralidade, a incerteza e o compromisso (teoria da história). Heller acredita que sua reflexão sobre consciência histórica prepara para a proposta maior: um projeto que é socialista porque baseado em liberdade, igualdade e fraternidade (e não na produção ou no capital). A partir daí, para ela, será possível atribuir sentido à história (por meio da historiografia) com base nos valores com os quais nos comprometemos.

Nessa interpretação, teoria da história e historiografia nunca são neutras, são parciais porque se colocarão sempre ao lado dos que mais sofrem. Isso permitirá encontrar regularidades entre as diferentes narrativas históricas, mas nunca leis deterministas. $\mathrm{O}$ progresso pode ser uma ideia reguladora que indica as decisões corretas a tomar, isto é, aquelas que não implicam em sofrimento humano.

Além disso, a manutenção do progresso como ideal mantém a noção de descontentamento, o qual conduz à reivindicação por liberdade e igualdade. Segundo a filósofa, perante o horror, todos sentem angústia - não por serem responsáveis diretos por ele, mas pelo sentimento de que poderiam ter feito algo para evitá-lo. Tal sentimento é mobilizador de ações individuais que podem motivar os demais e causar grandes impactos (HELLER, 1993, p. 366). A coragem cívica necessária para a mobilização não se constrói no vazio, mas no compromisso com valores e ideias que pareçam justos e racionais e, portanto, permitam a adesão dos outros, pois "a humanidade nunca produz valores que não possam ser observados e constantemente sustentados" (HELLER, 1993, p. 368). 
Nesse ponto, Heller recorre à noção de utopia. Como a teoria da história não pode formular projetos de futuro obrigatórios, precisa recorrer a "[...] uma imagem da universalização factual e da concretização daqueles próprios valores enraizados na segunda lógica da sociedade civil"4 (HELLER, 1993, p. 370). Nota-se um esforço, por parte da autora, em conciliar ideais abstratos à construção de novos futuros concretos (mais justos e mais igualitários) com respeito à democracia e à liberdade de engajamento. A realização da utopia implica num compromisso com o princípio de que nenhum ser humano pode servir de instrumento para nada. Quem assume tal compromisso sabe que será combatido por aqueles que se beneficiam do uso das pessoas para satisfação de suas próprias necessidades.

Para sair desse impasse, Heller recorre à argumentação racional (citando Apel e Habermas) e à obrigação de propor caminhos alternativos, que convidem os outros a partilhar da utopia e obriga à aceitação da pluralidade de posturas. Esse tipo de teoria da história não garantirá o êxito dos ideais, mas sustentará a perseverança de agir por eles.

Tendo isso em mente, devemos estabelecer objetivos adequados à ideia de uma utopia, não esperando o "acontecimento" desta utopia, mas contribuindo para a construção de um mundo que possa sustentar uma maior semelhança com ela do que este no qual vivemos. Se fizermos tudo o que podemos para criar um mundo, de algum modo, mais parecido com esta utopia do que nosso, haveremos de ter cumprido nosso dever, quer obtenhamos sucesso integral ou não. E, havendo cumprido o dever, poderemos usufruir nossa vida, a única que temos. (HELLER, 1993, p. 370, grifos originais).

Heller, portanto, reflete sobre consciência histórica para construir um projeto de ação e de compromisso com o futuro que

4 Em Heller, a segunda lógica da sociedade civil é socialista e se fundamenta nos ideais de liberdade, igualdade e fraternidade. 
não cai nas armadilhas da modernidade iluminista, mas tampouco abandona ideais que podem nos afastar do desespero e do relativismo irresponsável. Nossa interpretação sobre os processos de atribuição de sentido ao tempo sugeridos por Heller permite a aproximação com utopias político-educacionais enunciadas por professores de história em diversas pesquisas realizadas pelos autores entre 2009 e 2016. Nessas pesquisas, utopias políticoeducacionais ganham sentido concreto pela relação próxima com as vidas dos jovens estudantes e pelo sentimento de haver feito o certo e o possível para construir um mundo melhor, respeitando a pluralidade e o engajamento de cada um.

Minha utopia é que ninguém tenha que colocar o menino na escola particular para ter numa escola boa. Essa eu acho que é a maior de todas. Eu quero que todas as escolas sejam boas.

Quando eu comecei eu queria mudar o mundo. [...] E ao longo do tempo eu fui percebendo que [...] é meio que [...] semear [...] Eu luto para que todos eles cheguem numa determinada porta.

Améliorer l'égalité des chances de tous les élèves. Les préparer au mieux au monde de plus en plus complexe qui les entoure. Leur donner un sens critique réel.

É uma sementinha que eu me sinto na obrigação de plantar \{risos\}. Se isso vai influenciar ou não, como o espaço é curto, eu não consigo perceber, mas eu consigo perceber avanços, mesmo que seja sobre o conteúdo mesmo.

La relación que nos puede traer mejores consecuencias para todos es el pensar cómo vive cada uno y cómo podemos vivir conjuntamente, pero siendo mucho más empáticos, mucho más tolerantes.

[Melhorar] a relação deles com o ensino. Porque o aluno de EJA vem com uma autoestima muito baixa em relação à escola. 
História e Perspectivas, Uberlândia (57): 179-207, jul./dez. 2017

Dans l'idéal, apporter des enseignements supplémentaires qui permettent davantage l'émancipation des élèves, avec en tête l'éducation à l'écologie/ la nature et l'éducation à la politique (et pas seulement leur dire «il faut aller voter», qui n'est pas suffisant pour pouvoir se dire citoyen).

Eu sempre faço uma discussão inicial sobre: "por que a gente estuda história?" [...] Pra ver que história não é só coisa velha, que influencia no dia dele hoje. [...] É porque eu estou querendo prepará-los para pensar.

Yo creo que es un compromiso, como es ser profesor de historia y ciencias sociales, es un compromiso. Que adquieres con tu mundo, con tu sociedad, con tu entorno, con ... con tu presente, pues eso, con tu presente y con tu futuro y con el futuro de los demás.

(Testemunhos de professores de história brasileiros, espanhóis e franceses, recolhidos pelos autores entre 2011 e 2016).

Em Rüsen, essa concepção de um futuro aberto, que considera que o devir, bom ou ruim, resulta basicamente do conjunto das atitudes humanas e, portanto, passível de compromissos com acordos construídos socialmente e de elaboração de utopias, expressa-se com clareza na atitude abrangida pelo conceito de modo genético de produção do sentido, como veremos a seguir. Para Rüsen, ainda a utopia parece estar vinculada à própria operação da consciência histórica, no movimento de articulação entre a experiência interpretada do passado na ação do presente, articulada pela expectativa projetada de futuro. A projeção do futuro sempre traz um superávit de intencionalidade que é a estrutura básica da utopia. Quando se trata do movimento cotidiano da consciência histórica, a projeção de futuro é geralmente "conservadora" e calcada apenas nas possibilidades interpretadas como viáveis para a realidade entendida pelos sujeitos.

A utopia, por sua vez, vai além do que é visto como factível no momento, é o exagero da representação do que deveria ou poderia vir a ser (seja desejo, seja medo), para além do limite 
da plausibilidade, no sentido do inédito. Embora inviável no presente, a utopia também pode orientar ações que se acredite que promovam progressivamente sua a viabilidade.

A consciência utópica baseia-se num superávit de carências com respeito aos meios dados de sua satisfação. Ela possui a função vital de orientar a existência humana por representações que vão, por princípio, além do que é, empiricamente, o caso. Utopias funcionam como sonhos da consciência histórica sempre que se trata de articular conscientemente (despertas), como orientadoras do agir, representações de circunstâncias de vida desejáveis. As utopias são, pois, os sonhos que os homens têm de sonhar com toda a força de seu espírito, para conviver consigo mesmos e com seu mundo, sob a condição da experiência radical da limitação da vida. (RÜSEN, 2007b, p. 138).

\section{A historicidade do mundo e a consciência da história como responsabilidade planetária}

Nos anos 1980, ainda em plena ameaça de uma guerra nuclear entre norte-americanos e soviéticos, a série de televisão Cosmos abriu as janelas do pensamento científico a meio bilhão de terráqueos que assistiram à série. A série foi concebida e realizada por Anne Druyan e Carl Sagan, este também o apresentador dos episódios. No último deles, Sagan afirmava: somos nós que respondemos pela terra, nós temos a responsabilidade, como resultantes de todo o movimento e evolução oriundos do Cosmos, de sobreviver e garantir que a nossa espécie continue a buscar suas origens, em uma convivência cada vez mais saudável e empática com os semelhantes, as demais formas de vida e com o próprio universo. Parece-nos que é esse o espírito daquilo que Heller chama de "responsabilidade planetária", que só é possível de construir no modo empático e relativista de produção de sentido histórico que Rüsen batizou como "genético" e que Heller soluciona com a utopia. 
Quem ensina história, principalmente na escola, está envolvido em relações temporais complexas. Como cidadão, procura compreender seu mundo, posicionar-se, agir politicamente, tomar decisões de ordem pessoal. De outro lado, é educador: trabalha com jovens que são muito diversos. Elementos de futuro, de esperança, de tradição e de renovação envolvem suas escolhas profissionais. Por fim, é um educador que ensina história: a organização do trabalho pedagógico específico do ensino de história também passa pelas formas como cada professor combina seus referenciais teórico-metodológicos, suas experiências com os estudantes e suas utopias político-educacionais, entre outros elementos.

A falência do projeto moderno e a recusa da confusão da consciência histórica estabelecem, tanto para Heller quanto para Rüsen, uma tarefa dupla: a compreensão da pós-modernidade, por um lado, e a proposição de um modo de orientar-se nela. Superadas, todas as doutrinas que propõem de algum modo a suspensão do juízo a partir da adesão a qualquer código que se ofereça como válido por estar fora ou acima do tempo ou da historicidade, a esfinge se põe uma vez mais diante de nós e, em especial, diante de quem pretende ensinar história na escola, em que as demandas sociais de diversos grupos outrora excluídos das narrativas oficiais se fazem ouvir e para as quais, por vezes, a historiografia acadêmica não possui todas as respostas.

O estágio que surge na atualidade, segundo Heller, é a generalidade refletida enquanto tarefa, quer dizer, a condição humana, embora acessível a todos, tem sido restringida, pelas nossas próprias ações como espécie, a uma parte apenas da humanidade. Assim, a generalidade refletida só existe como projeto que se constrói e se reconstitui continuamente. Caracteriza este estágio de consciência de que a razão não é absoluta sem valores, e que os valores devem ser construídos no diálogo e sem imposição de pressupostos que não possam ser discutidos, bem como o desejo de construir condições de vida em comum respeitando as diferenças. A razão, assim como a verdade, não é absoluta, nem inacessível coletivamente, ao ficar encerrada 
em mundos particulares, mas sim relacional, ou seja, construída sobre o alicerce dos consensos possíveis, ou segundo Rüsen, "racional" no sentido do caráter argumentativo indissociável da cientificidade (RÜSEN, 1989, p. 323). Com a consciência de que a razão também produziu dominação, novas dependências e insensatez, e portanto longe de um culto acrítico à ciência, é possível identificar no modo genético de produção de sentido alguns elementos comuns com aspectos caros à cientificidade: a historicidade e a provisoriedade dos conhecimentos e enunciados, a força do melhor argumento e o diálogo ou intersubjetividade na definição dos consensos possíveis. O que Heller pode aportar, num tom mais político, é que todo esse aparato faz sentido na perspectiva de produzir consensos que evitem o sofrimento e maximizem a felicidade possível.

Trata-se de uma perspectiva ao mesmo tempo esperançosa e ciente/cética de sua frágil condição, dependente dos sucessos e consensos construídos, compreensão em que se nota, mais uma vez, a influência da concepção de política e de milagre de Arendt. Embora tal pensadora evite o uso da palavra "utopia", entendemos que ela não recusa a necessária esperança de que futuros possíveis sempre podem ser construídos, ao mesmo tempo em que se preservam aqueles aspectos do mundo que ainda nos são caros. Esta necessidade de preservação se expressa, por exemplo, na recusa de Heller em excluir a democracia e a pluralidade de seu pensamento.

Diante dos desafios da pós-modernidade, também Rüsen busca suas respostas. Em seus textos publicados no Brasil, respectivamente em 1989 e 1997, realiza um balanço parecido entre a persistência da possibilidade da razão na História e as encruzilhadas do pensamento pós-moderno. Além disso, postulamos que o conceito de modo genético de produção de sentido histórico seja equivalente, em grande parte, à ideia helleriana de consciência da generalidade refletida como tarefa, ou responsabilidade planetária. Percebe-se a incorporação da crítica pós-moderna ao papel político e social da história - deslocamento do paradigma sem abandonar a possibilidade de razão e verdade, 
mas também sem negar o papel do não racional, afetivo e ficcional.

O modo genético de geração de sentido histórico reúne as condições para a orientação temporal do sujeito no contexto pós-moderno. Entende e aceita a mudança como o componente essencial do tempo, compreende e assimila a historicidade de todo discurso e de toda instituição como condições da leitura do mundo e de sua escritura. Reticente a qualquer sistema que estabeleça o monopólio da produção de verdades absolutas, resiste também à confusão e à desorientação que resultam tanto da negação da possibilidade de verdade quanto da fragmentação da mesma para cada microcosmo identitário, espaços isolados em que as verdades privadas encontram validade circunscrita. Entretanto, Rüsen não estende suas considerações sobre o futuro ou a utopia de forma tão incisiva quanto Heller, que reitera, em sua teoria da história, que seu ponto de vista é ao lado dos que mais sofrem. Além disso, ela convida os leitores a se mobilizarem da mesma forma e expressa sua profissão de fé sobre um mundo melhor do que hoje: "nosso século não há de terminar do mesmo modo vergonhoso como começou e desenrolou-se" (HELLER, 1993, p. 366).

\section{Referências}

ARENDT, Hannah. Responsabilidade e julgamento. São Paulo: Companhia das Letras, 2004.

ASSIS, Arthur. A teoria da história de Jörn Rüsen: uma introdução. Goiânia: Editora da UFG, 2010.

BACZKO, Bronislaw. Utopia. In: ENCICLOPÉDIA Einaudi. Lisboa: Anthropos Homem, 1989. v. 5, p. 67-101.

BAROM, William Carlos Cipriani. Didática da história e consciência histórica: pesquisas na pós-graduação brasileira (2001-2009). 2012. 135f. Dissertação (Mestrado em Educação) - Programa de PósGraduação em Educação, Universidade Estadual de Ponta Grossa, Ponta Grossa, 2012. 
CARDOSO, Oldimar. Para uma definição de didática da história. Revista Brasileira de História, São Paulo, v. 28, n. 55, p. 153-170, 2008.

CERRI, Luis Fernando. Os conceitos de consciência histórica e os desafios da Didática da História. Revista de História Regional, Ponta Grossa, v. 6, p. 93-112, 2001.

CHAUÍ, Marilena. Notas sobre utopia. Ciência e Cultura, São Paulo, v. 60, p. 7-12, jul. 2008. Disponível em: <http://cienciaecultura.bvs.br/pdf/ cic/v60nspe1/a0360ns1.pdf>. Acesso em: 29 jul. 2016.

DUARTE, Newton. A pesquisa e a formação de intelectuais críticos na pós-graduação em educação. Perspectiva, Florianópolis, v. 24, n. 1, p. 89-110, jan./jun. 2006. Disponível em: <https://periodicos.ufsc.br/index. php/perspectiva/article/view/10313>. Acesso em: 11 dez. 2015.

GADAMER, Hans-Georg. Problemas epistemológicos das ciências humanas. In: - O problema da consciência histórica. Rio de Janeiro: Editora da Fundação Getúlio Vargas, 1998.

GRANJO, Maria Helena Bittencourt. Agnes Heller. Filosofia, moral e educação. Petrópolis: Vozes, 2008.

GUIMARÃES, Gleny Terezinha Duro (Org.). Aspectos da teoria do cotidiano: Agnes Heller em perspectiva. Porto Alegre: EDIPUCRS, 2002.

HELLER, Agnes. Uma teoria da História. Rio de Janeiro, Paz e Terra, 1992.

HELLER, Agnes; FÉHER, Ferenc. A condição política pós-moderna. Rio de Janeiro: Civilização Brasileira, 1998.

KUHN, Thomas. A estrutura das revoluções científicas. São Paulo: Perspectiva, 1998.

LAVILLE, Christian. Em educação histórica, a memória não vale a razão! Educação em Revista, Curitiba, v. 41, p. 12-39, 2005.

ORTEGA, Francisco. Biopolíticas da saúde: reflexões a partir de Michel Foucault, Agnes Heller e Hannah Arendt. Interface, Botucatu, v. 8, n. 14, p. 9-20, set.2003/fev. 2004. Disponível em: <http://www.scielo.br/scielo. php?pid=S1414-32832004000100002\&script=sci_abstract\&tlng=pt $>$. Acesso em: 11 dez. 2015. 
PARANÁ. Secretaria de Estado da Educação. Diretrizes curriculares para o ensino de história nos anos finais do Ensino Fundamental e no Ensino Médio. Curitiba: SEED, 2015. Disponível em: <http://www. educadores.diaadia.pr.gov.br/arquivos/File/diretrizes/dce_hist.pdf>. Acesso em 5 out. 2015.

RÜSEN, Jörn. Conscientização histórica frente à pós-modernidade: a História na era da "nova intransparência". História: questões e debates, Curitiba, v. 10, n. 18-19, p. 303-328, jan./dez. 1989.

RÜSEN, Jörn. Cultura faz sentido. Orientações entre o ontem e o amanhã. Petrópolis: Vozes, 2014.

Didática da história: passado, presente e perspectivas a partir do caso alemão. Práxis Educativa, Ponta Grossa, v. 1, n. 2, p. 7-16, jul./dez. 2006.

História entre a modernidade a pós-modernidade. História: questões e debates, Curitiba, v. 14, n. 26-27, p. 80-101, jan./dez. 1997.

História viva. Teoria da História III: formas e funções do conhecimento histórico. Brasília: Editora da Universidade de Brasília, 2007b.

Razão Histórica. Teoria da História: os fundamentos da ciência Histórica. Brasília: Editora UnB, 2001.

Reconstrução do passado. Teoria da História II: os princípios da pesquisa histórica. Brasília: Editora UnB, 2007a.

SADDI, Rafael. Didática da história naAlemanha e no Brasil: considerações sobre o ambiente de surgimento da Neu Geschichtsdidaktik na Alemanha e os desafios da nova didática da história no Brasil. Opsis, Catalão, v. 14, n. 2, p. 133-147, jul./dez. 2014.

SEVILLA, Sergio. Historia y postmodernidad: el diagnóstico de Ágnes Heller. Daimon, Murcia, n. 17, p. 85-99, 1998. Disponível em: <http:// revistas.um.es/daimon/article/viewFile/9511/9261>. Acesso em: 17 out. 2010. 
SILVA, Vandeí Pinto da. Cotidiano e filosofia no ensino médio: mediações. In: REUNIÃO ANUAL DA ANPEd, 28., 2005, Caxambu. Anais... Caxambu: Associação Nacional de Pesquisa e Pós-Graduação em Educação, 2005. Disponível em: <http://www.anped.org.br/reunioes/28/ textos/gt17/gt171317int.rtf>. Acesso em: 11 dez. 2015.

TORMEY, Simon. From "rational utopia" to "will-to-utopia": on the "postmodern" turn in the recent work of Agnes Heller. Daimon, Murcia, n. 17, p. 133-149, 1998. Disponível em: <http://eprints.nottingham. ac.uk/29/>. Acesso em: 11 dez. 2015.

Recebido em agosto de 2016.

Aprovado em junho de 2017. 